\section{Causes Of Congenital Anomalies In Children And The Role Of Nursing In It}

\author{
Mirzarakhimova Kamola Rikhsiyevna \\ Assistant, Tashkent State Dental Institute, The \\ Department Of Public Health, Management Health And \\ Physical Culture, Uzbekistan \\ Nurmamatova Qurbonoy Choriyevna \\ Assistant, Tashkent State Dental Institute, The \\ Department Of Public Health, Management Health And \\ Physical Culture, Uzbekistan \\ Turakhanova Feruza Muhtorkhan qizi \\ Assistant, Tashkent State Dental Institute, The \\ Department Of Public Health, Management Health And \\ Physical Culture, Uzbekistan \\ Abdashimov Zafar Bahtiyarovich \\ Associate Professor, Tashkent State Dental Institute, \\ The Department Of Public Health, Management Health And \\ Physical Culture, Uzbekistan
}

\section{G open ACCESS}

The American Journal of Medical Sciences And Pharmaceutical

Research

JULY 2020

Page No.: 52-72

Volume-II Issue-VII

PUBLISHED: 30 JULY 2020

www.usajournalshub.com/inde

x.php/TAJMSPR

Copyright: Original content from this work may be used under the terms of the

Creative Commons Attribution

4.0 licence.

\title{
Abstract
}

In world congenital anomalies are serious medical and social problem. They doubled over decade 20th century and played significant role in the structure pathology and mortality in the infant, perinatal and children. Now time is 1800 out of 10,000 children born with congenital anomalies. Through progress made in our country in the future reform health system strengthening and the protection of the health children, congenital abnormalities play leading role in the structure morbidity disability and mortality. Reasons development of $40-60 \%$ anomalies is unknown. 
Keywords: congenital anomalies, patronage nursing, congenital dental anomalies.

\section{Annotation}

Congenital anomalies in children is the most important medical and social problem in health care. Many of the children with developmental disabilities die in the first months and years of life, and most of the survivors need constant medical and social assistance.

Health, including the health of the fetus and the child, is an integral value determined by a number of objective factors, independent of the influence of a person, and factors that depend on his activities.

\section{Introduction}

Apply the term "sporadic the defect of birth", meaning unknown cause, accidental appearance and low risk re appearance have future children. For $20-25 \%$ of anomalies more likely "multi-factor" reason - complex interaction many small genetic defects and risk factors environmental environment. The rest $10-13 \%$ of anomalies associated with the influence environment. Only $12-25 \%$ of anomalies have purely genetic causes [3]. Statistics shows disproportionate a high proportion of the total number survivors newborns premature children who suffer physical, intellectual and emotional disability. Prematurity leads to the emergence of problems with the cost and effectiveness treatment with relationship in the family, difficulties when training and further employment. Prematurity-not only medical but serious social an issue where women often do not have access to enough the number good food and may be subject effects any agent or factor, for example, of infection or alcohol, which provokes or enhances deviations from the norm in prenatal development. More also, motherhood in adulthood increases the risk chromosomal abnormalities including down syndrome, while motherhood at a young age increases the risk some congenital malformations.

\section{Goal Research}

Development the system of scientific reasonable measures to improve efficiency work nursing nurses at the study of factors risk and prevalence congenital anomalies at through an integrated socio-hygienic research.

\section{Results Research}

According domestic and foreign literature pediatricians can make a the contribution of the early diagnosis many hereditary diseases and syndromes. Intrauterine violations 
THE AMERICAN JOURNAL OF MEDICAL SCIENCES AND PHARMACEUTICAL RESEARCH

ISSN (e): 2689-1026

DOI: https://doi.org/10.37547/TAJMSPR/Volume02Issue07-09

development form a number of anomalies, included many syndromes multiple malformations extra chromosomal etiology and almost all chromosomal disease.

Common Was The Incidence Of Have Children 0-14 And 15-17 Years Of Age With Congenital Anomalies (Defects Development), Deformity And Chromosomal Abnormalities (On 100000 Population)

Table 1.

\begin{tabular}{|c|c|c|c|c|c|c|c|c|}
\hline \multirow{3}{*}{ Name of regions } & \multicolumn{8}{|c|}{ Defects development } \\
\hline & \multicolumn{2}{|l|}{$2015 y$} & \multicolumn{2}{|l|}{$2016 y$} & \multicolumn{2}{|c|}{$2017 y$} & \multicolumn{2}{|l|}{$2018 y$} \\
\hline & 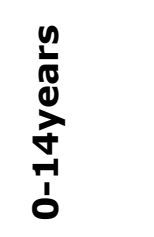 & ำ & \begin{tabular}{l}
$n$ \\
$\frac{n}{0}$ \\
0 \\
\multirow{2}{*}{} \\
-1 \\
$\vdots$ \\
0
\end{tabular} & ம் & 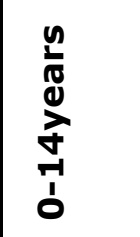 & ก่ & 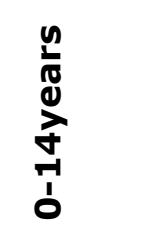 & خे \\
\hline Tashkent city & 1464,2 & 363,1 & 1317,7 & 333,3 & $\begin{array}{l}1370 \\
0\end{array}$ & 313,2 & 1138,1 & 256,7 \\
\hline Andijan region & 349,3 & 230,0 & 348,7 & 320,6 & 334,5 & 269,9 & 285,3 & 276,8 \\
\hline Bukhara region & 627,4 & 448,2 & 496,0 & 271,9 & 492,4 & 257,6 & 497,0 & 174,8 \\
\hline Jizzakh region & 264,2 & 165,3 & 214,5 & 128,2 & 217,1 & 71,3 & 134,4 & 289,2 \\
\hline Kashkadarya region & 476,8 & 130,4 & 465,1 & 167,2 & 433,4 & 183,6 & 411,4 & 147,7 \\
\hline Navoi region & 599,3 & 229,9 & 617,5 & 203,6 & 615,0 & 266,4 & 478,4 & 195,5 \\
\hline Namangan region & 520,1 & 294,9 & 508,1 & 254,2 & 476,6 & 234,5 & 464,1 & 335,0 \\
\hline Samarkand region & 615,5 & 257,6 & 544,4 & 206,0 & 602,0 & 329,0 & 890,2 & 366,1 \\
\hline Surkhandarya region & 404,0 & 191,5 & 231,7 & 224,7 & 298,4 & 274,3 & 352,5 & 203,8 \\
\hline Sirdarya region & 401,7 & 209,5 & 394,9 & 214,2 & 392,9 & 232,4 & 397,6 & 200,2 \\
\hline Tashkent region & 9949,2 & 810,2 & 960,3 & 458,5 & $\begin{array}{l}1014, \\
1\end{array}$ & 415,4 & 928,3 & 419,3 \\
\hline Ferghana region & 885,6 & 296,8 & 894,9 & 396,9 & 819,8 & 267,6 & 1021,8 & 377,5 \\
\hline Xorezm region & 619,7 & 298,1 & 393,7 & 206,0 & 393,6 & 170,6 & 386,1 & 155,8 \\
\hline Republicof Karakalpakstan & 334,4 & 131,7 & 325,7 & 121,5 & 294,1 & 102,5 & 301,6 & 84,1 \\
\hline Republic of Uzbekistan & 629,0 & 295,2 & 571,5 & 261,7 & 574,6 & 252,3 & 598,8 & 264,5 \\
\hline
\end{tabular}




\section{ISSN (e): 2689-1026}

DOI: https://doi.org/10.37547/TAJMSPR/Volume02Issue07-09

In many studies it was established, what is the frequency the appearance of those or other congenital malformations depends on the sex of the child (table 2). For example, pyloric stenosis and clavate stop often meet boys whereas congenital hip dislocation 4-5 times more likely to have girls. Among children with one kidney, about twice boys whereas among children with three kidneys approximately 2.5 times more girls. The same the picture is among newborns children with excess number of edges, vertebrae teeth and other organs, undergone in the process evolution reduction numbers, oligomerization,among them, more than girls. Among same newborn shortages, on the contrary, more boys. Anencephaly twice as often found girls. Excess muscle 1.5 times often detected in the corpses of men, than women. The number of boys born with 6th finger 2 times the number of girls. The predominance of male it was noted for vices phylogenetically younger organs and systems bodies. In terms etiology sex differences you can divide appear before and after differentiation male gonads in the process embryonic development, which starts from the eighteenth weeks. Level testosterone in male embryos this significantly increases. Subsequent hormonal and physiological differences male and female fetuses can you explain some sex differences the incidence of congenital vices [2].

Table 2.

\begin{tabular}{|c|c|}
\hline Congenital Vice & $\begin{array}{c}\text { The } \\
\text { ratio floors } M: F\end{array}$ \\
\hline \multicolumn{2}{|l|}{ Vices with the prevalence of female } \\
\hline Congenitalhipdislocation & $1: 5.2^{[1]} ; 1: 5^{[2]} ; 1: 8^{[3]}$ \\
\hline Anencephaly & $1: 1.9^{[1]} ; 1: 2^{[4]}$ \\
\hline Traumaticbrainhernia & $1: 1.8^{[1]}$ \\
\hline Spinalhernia & $1: 1.4^{[1]}$ \\
\hline Aplasiaofthelung & $1: 1.51^{[1]}$ \\
\hline Diverticulaoftheesophagus & $1: 1.4^{[1]}$ \\
\hline Stomach & $1: 1.4^{[1]}$ \\
\hline \multicolumn{2}{|l|}{ NeutralVice } \\
\hline Underdevelopment the tibia and femoral bones & $1: 1.2^{[1]}$ \\
\hline Atresiaofsmallintestine & $1: 1^{[1]}$ \\
\hline Esophagealatresia & $1.3: 1^{[1]}$ \\
\hline \multicolumn{2}{|l|}{ Vices with a predominance of the male } \\
\hline Cleftlip & $2: 1^{[2]}$ \\
\hline Pylorostenosis & $5: 1^{[2]} ; 5.4: 1^{[3]}$ \\
\hline Meckel'sdiverticulum & Moreoften boys ${ }^{[1]}$ \\
\hline Diverticulaofthecolon & $1.5: 1^{[1]}$ \\
\hline Atresiaoftherectum & $1.5: 1^{[1]}$ \\
\hline Bilateralrenalagenesis & $2.6: 1^{[1]}$ \\
\hline Unilateralrenalagenesis & $2: 1^{[1]}$ \\
\hline Bladderexstrophy & $2: 1^{[1]}$ \\
\hline $\begin{array}{l}\begin{array}{l}\text { Congenital violations patency the } \\
\text { congenital anomalies ureter }\end{array} \\
\text { renal }\end{array}$ & $2.4: 1^{[3]}$ \\
\hline CongenitalMegacolon & Moreoften boys ${ }^{[1]}$ \\
\hline Allmalformations & $1.29: 1^{[3]}$ \\
\hline
\end{tabular}


Have children born with hereditary diseases in the structure pathology revealed the predominance of malformations CNS (32\%) and congenital pathology heart (23\%). $2 \%$ newborns anomalies of development was multiple. With the greatest frequency among factor frequency $(7.6 \%$ and $8,4 \%)$ was observed malformations gastrointestinal injury risk met the threat of termination pregnancy early stages $(35 \%)$, spontaneous miscarriages in history (19\%), professional hazards and environmentally adverse living conditions (16\%). Research the level of alpha-fetoprotein serum blood pregnant showed it the increase in 10 patients and at 2 in the dynamics (18 and 22 weeks of pregnancy), what was indication to conduct amniocentesis. Great value during the examination risk had genetic advice which determine indications for more detailed survey. Revealed when karyotyping chromosomal anomalies $17 \%$ pregnant was indication or karyotyping of the fetus. In this case $2 \backslash 3$ of the fruit was discovered various chromosomal anomalies (balanced and unbalanced anomalies syndrome Patau).

Health family always was one of the main values of any society. However, the main subject the protection of this health taken to consider medicine, while health functions are an integral composite part of the family roles.

With the other hand, medicine itself always focused specific the patient or group of patients, differentiated in nosology, the clinical severity manifestations professional and social criteria. The family proclaimed, but was not separate the object of medical care.[9]

In General research into family problems and marriage has how in the world classic thoughts and modern the science is very high level. Almost each researcher it is possible to identify more or less detailed position on these issues. However, as may seem strange, when near considering it turns out the family as such, practically, has not been the subject sociology medicine.

Below to give socio-hygienic description of the families we spent survey of families of the children born with congenital defects in 200 healthy and 200 families with congenital anomalies in clinics in 2 areas of Tashkent. 
The study such factors as a way of life families conditions life and medical activity parents found that these factors affect birth children with congenital anomalies. First of all, hereditary diseases in the family, children with congenital anomalies, including these families in "the families of high risk", and reduces the risk of birth healthy the child in this the family, including results our study. $14 \%$ of households had children with congenital anomalies, while $17 \%$ of households had predisposition to hereditary diseases.

Figure 1. The presence of children with congenital anomalies in families and the percentage of families tend to hereditary diseases.

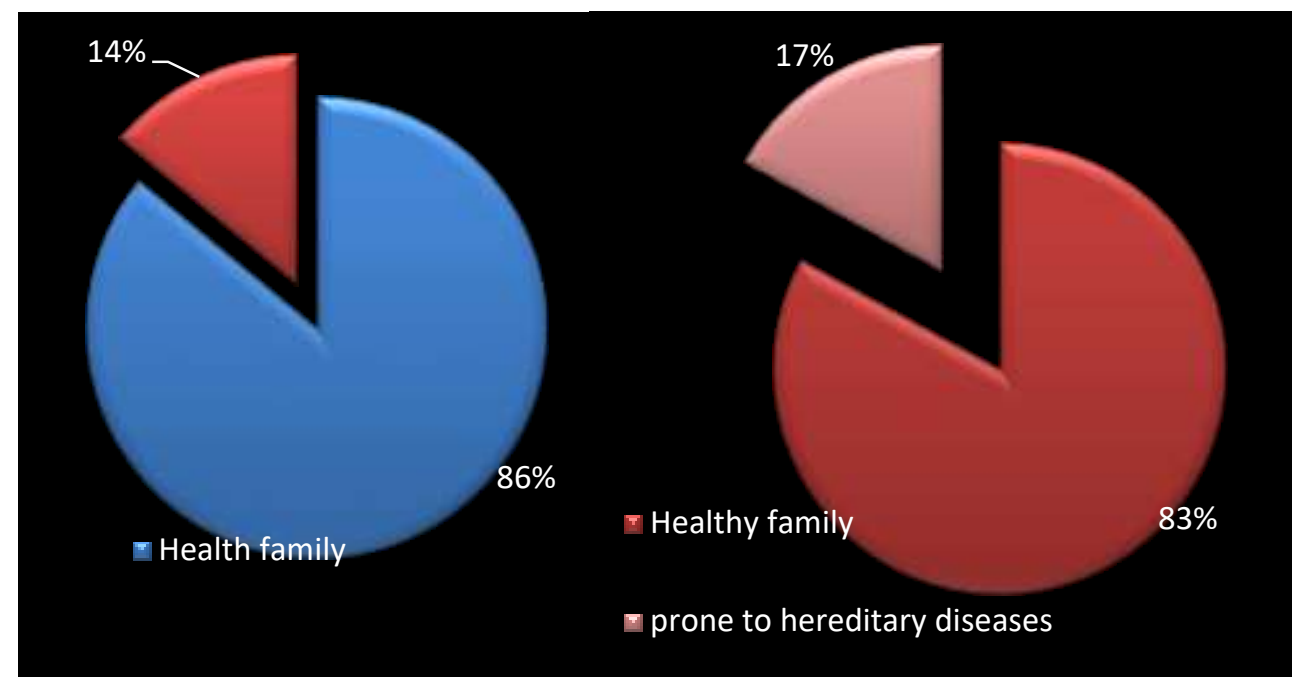

Among biological factors interval between births is one factor that much affect health children. It noted that indicators children's health inversely proportional the interval between births, and the less the interval, the higher risk of having children with defects development. About in $70 \%$ of cases children born with interval up to 3 years.

Results the survey showed the interval between births was 3 year and more $6 \%$ of mothers, 2-3 year, 24\% of mothers, $1-2$ years $30 \%$ and even 1 year between births in $40 \%$ of cases. 


\section{Figure 2. The interval between birth (\%).}

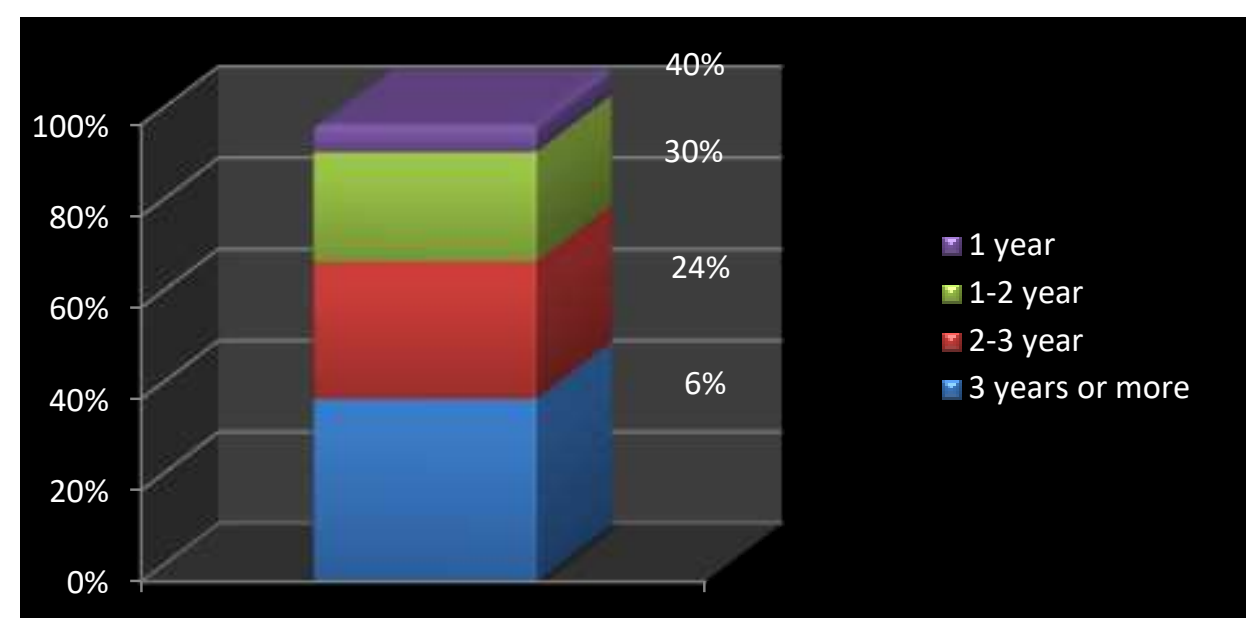

Given negative the I pact of marriage between close relatives health children, we thought it necessary to study it. Our study showed that children from families parents were connected, had 4.0 times more chances to be born with congenital anomalies, than children from families whose parents were not related. It was established, that $74.0 \%$ of children born with congenital the defects were close relatives their parents and of $20.0 \%$ was far relatives (Figure 3.).

Figure 3. Marriage between relatives (\%).

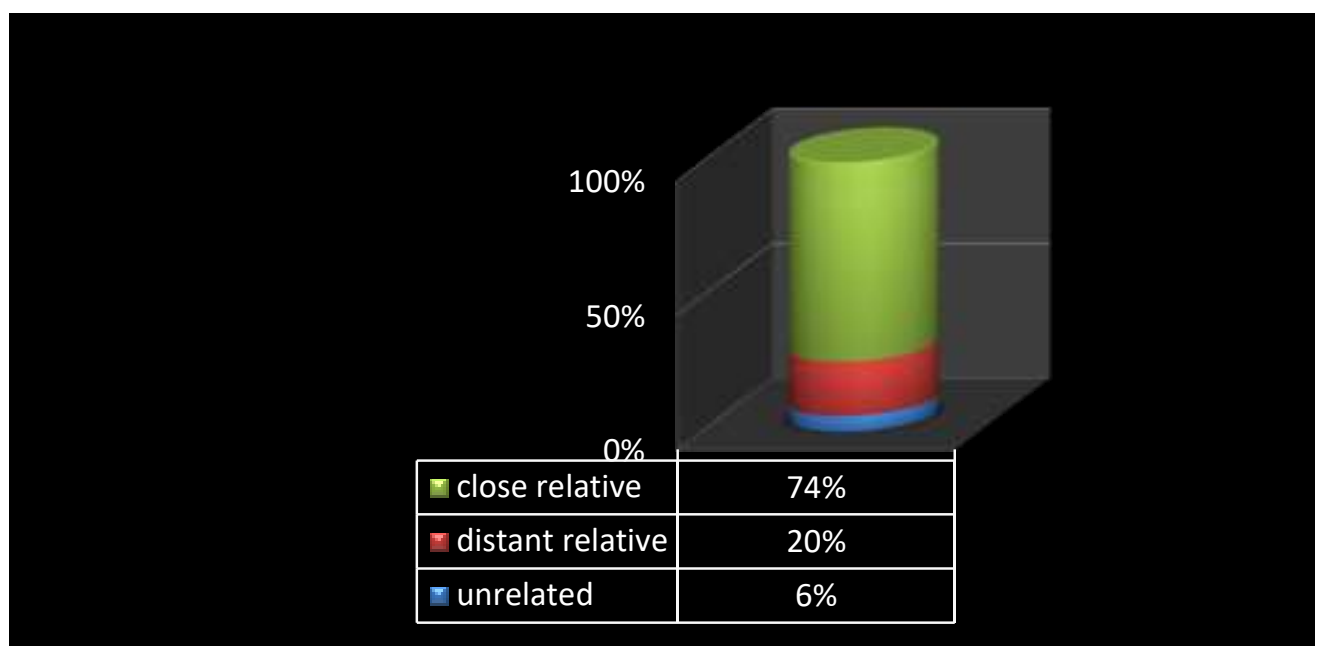


Health parents determines the health of the family. It was established, that the presence of chronic diseases parents $r$ children of families where one of the parents often suffers from acute diseases 2.0 times higher than children, born from healthy parents. Received data showed the birth children with various hereditary diseases extra genital disease the mother at the development of congenital abnormalities(anemia, nephropathy, gynecological disease), pregnancy (toxemia, preeclampsia) strongly influenced by health children.

In the process of learning health and social factors revealed during pregnancy mother with chronic and gynecological diseases was most that, of course, impact health unborn child. $24.8 \%$ of mothers had anemia in history when birth, $27,3 \%$ had various infectious disease 10.4 per cent had the disease kidney and $5.3 \%$ had heart disease. All this has impact on health future child.

Figure Maternal related disease during pregnancy.

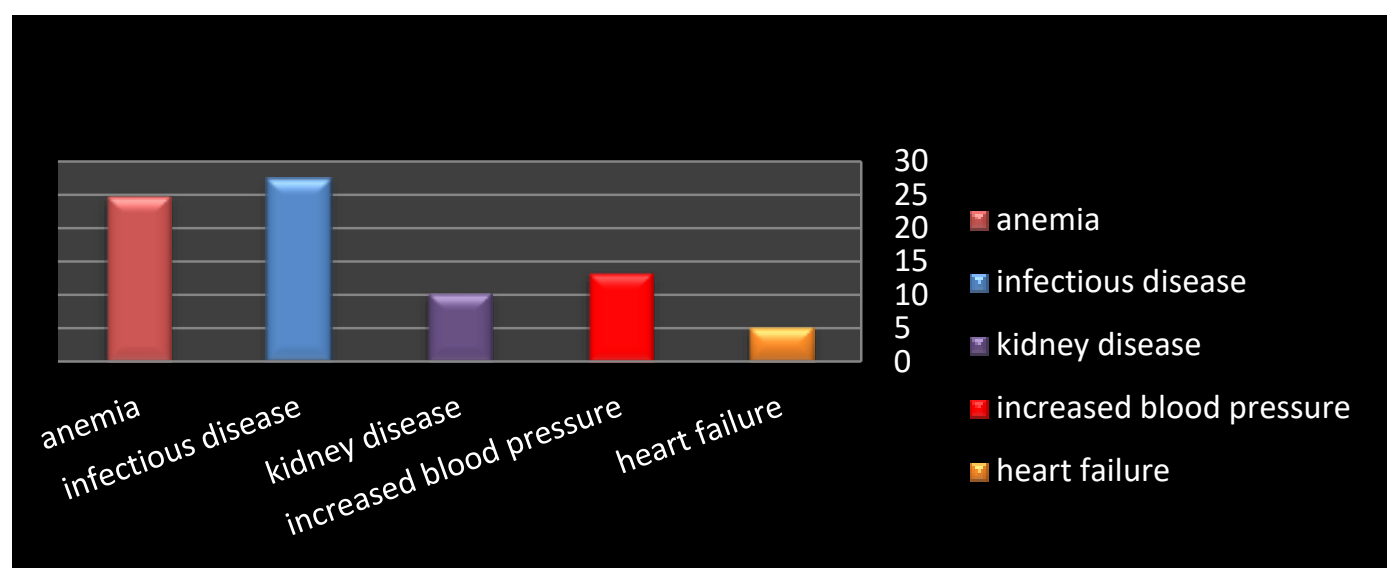

If pregnancy complicated complications (the risk of miscarriage, toxicity in pregnancy)or if the child he was born with asphyxia, congenital defects, was detected, the risk of birth defects in 2.0 times higher than in children with normal pregnancy and uncomplicated childbirth. In particular, health the child negatively affected by the previous pregnancy the mother, in fact the number of abortion $(3,0 \%)$, miscarriage $(5,0 \%)$, pathological childbirth $(10,0 \%)$, stillbirth (2.3 percent)., $49.2 \%$ of mothers had obvious toxicities in pregnancy, $17,2 \%$ had a risk miscarriage and $26.1 \%$ of mothers had bleeding in the first and second half pregnancy.

Results our research showed that the age of the mother during child birth also has significant impact on the health of children. In particular, if the mother is younger 19 years and older 40 years old increases the risk of birth defects, congenital anomalies. 
Figure 5. The age of the mother at the time of delivery

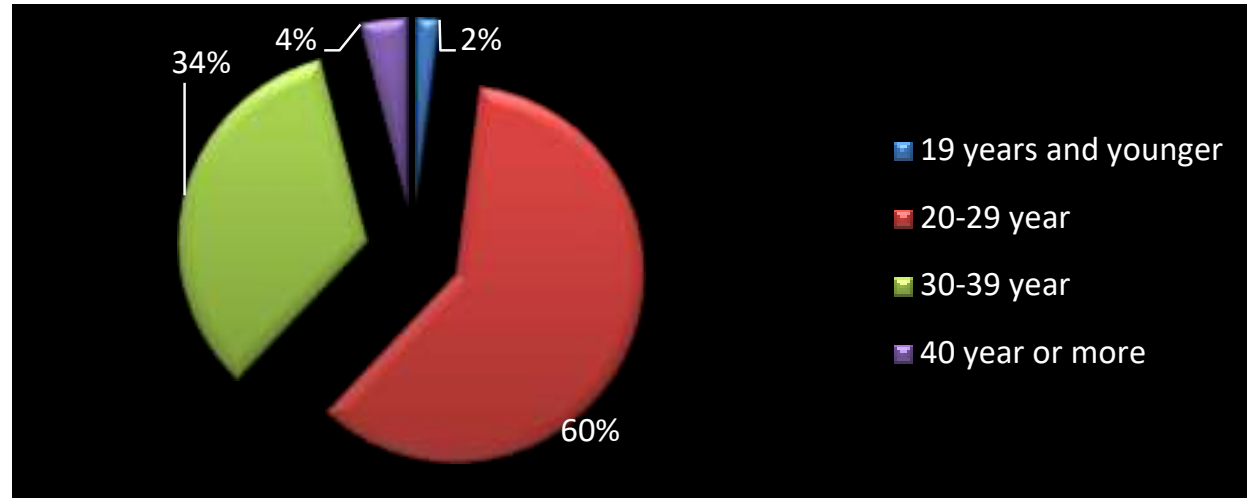

According to the study, $60 \%$ of children were born mothers in age $20-29$ years, and $34 \%$ of mothers at the age of 30-39 years, and 2\% of children born from mothers in the age 40 years and older.

It detected, that $30 \%$ of children born from the first birth 31.1 per cent of the second birth, $23.5 \%$ of the third born $10.8 \%$ of the fourth birth and $3.9 \%$ from the fifth birth.

Education parents medical knowledge is great value in a healthy the birth of children their correct care and education. In the study level of education mothers were marked with the following results: $30 \%$ with higher education, $60 \%$ with an average special education $10 \%$ with an average education.

Figure 6. Level education and social the status of mothers

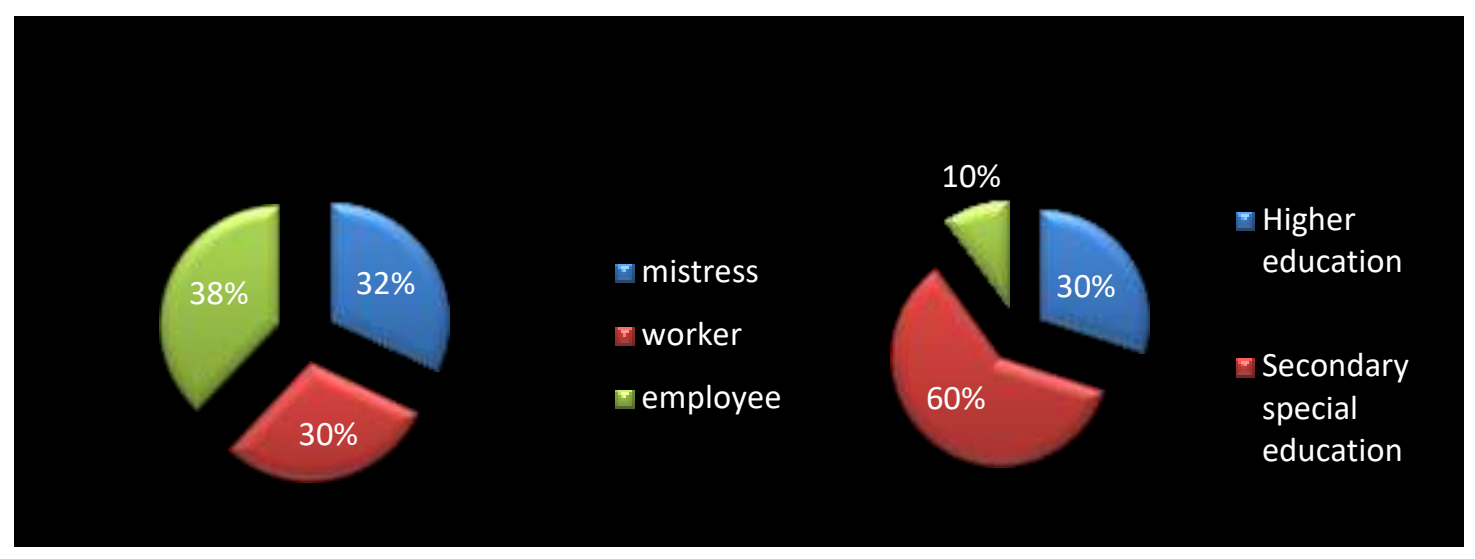


If we'll see social the status of mothers, $30 \%$ of mothers belonged to the working group, $38 \%$ - to the employees and $32 \%$ for Housewives.

Correlation between the children's incidence and conditions life was featured in a number the same research. Family conditions life (house) have directimpact on health members family and have great value in medicine and health as conducive the development of some diseases. So every employee health especially physicians working in preventive performance to be able to accurately assess living conditions a family to do appropriate insights and develop prevention diseases. Results our research showed that the lower the quality description of home conditions, the above incidence children, among the $21.7 \%$ of families with children with congenital malformations poor in a home setting.

Fight Smoking so as important to children as for adults, in the formation of healthy lifestyle and prevention diseases. While Smoking parents impact on health children since pregnancy children become directly passive smokers after birth, and impact this bad habits still more. $20 \%$ of parents with children with congenital defects have bad habits and $98 \%$ of fathers are often use alcohol.

One factor negative affect the condition the health of children, is mental the condition in family or interaction members of the family. To assess mental condition, we divided all surveyed family into 2 groups: Group 1- family with mental condition in the family, relationship satisfactory that is, in the family there are parents, the relationship between good family no harmful habits.

If no one in the family parents or if they often there differences if one of family members addicted to bad habits, we have classified these families as group 2 Relations in family unsatisfactory in a bad mood. It was established, the risk children in families mental condition which was evaluated as unsatisfactory 3 times higher than in families mental condition which was unsatisfactory.

\section{Figure 7. The presence of bad habits in family and mental condition (\%).}

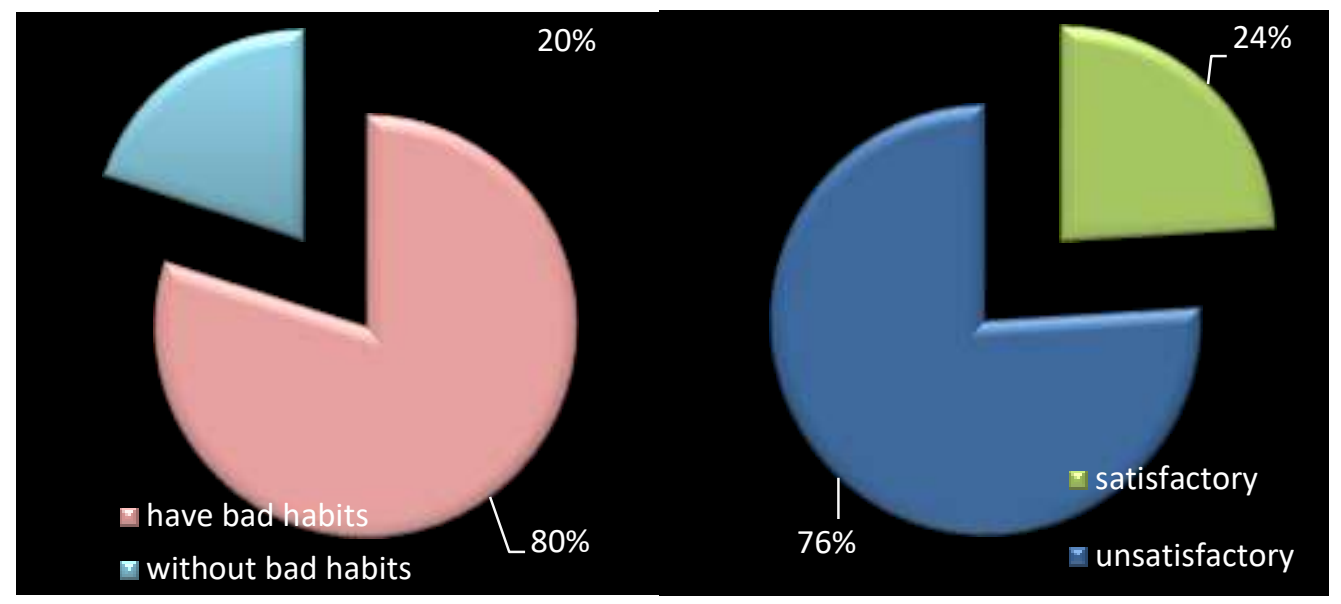


Regular physical exercises play an important role in strengthening the health of parents and the formation of the health of children, including study which showed, that $51 \%$ of parents don't do sports.

\section{Figure 8. Parents should do sports and observe diet}

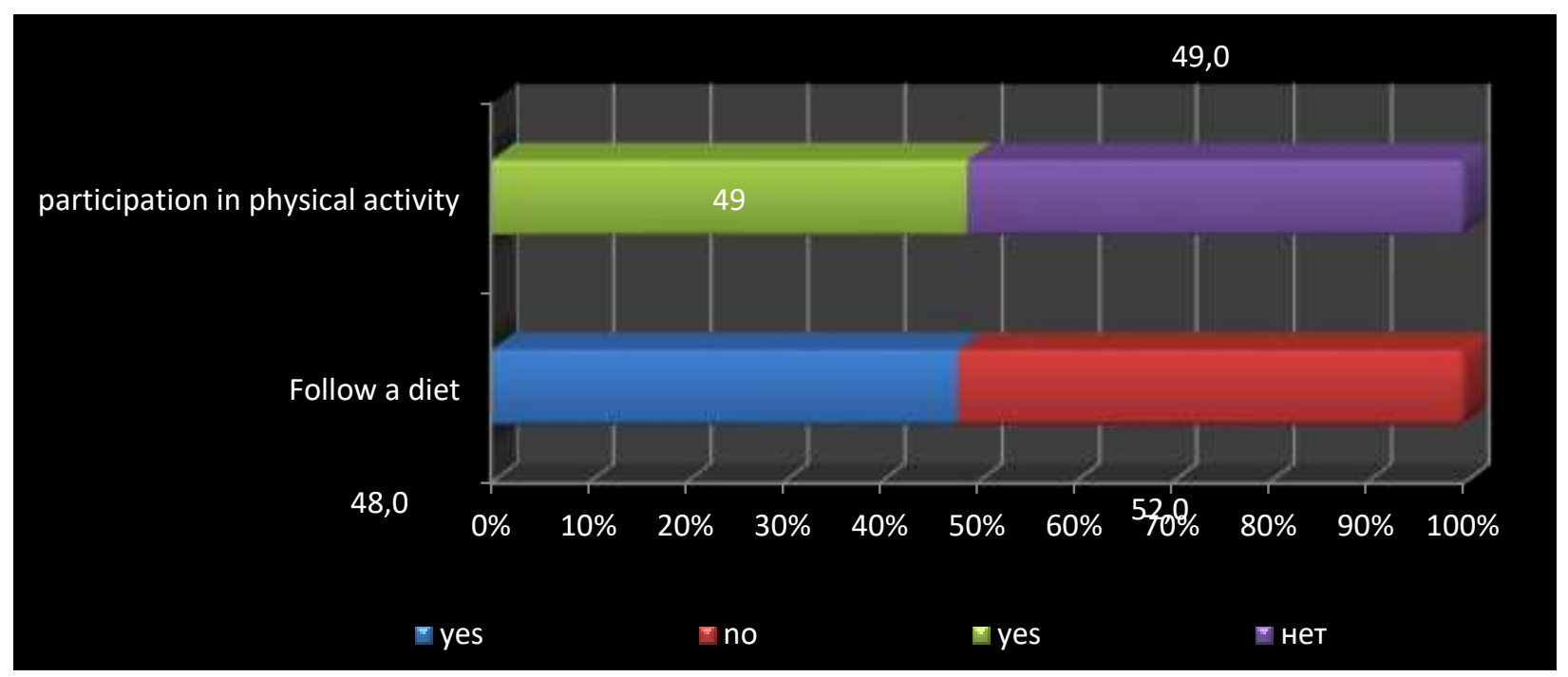

Right food in pregnancy, right the organization rest, following recommendations doctor play an important role in a healthy the growth of the fetus, the birth of a healthy child. Results the survey showed $52 \%$ of mothers didn't pay attention to your diet and rest during pregnancy. This, in turn, leads to the birth of children with congenital malformations.

Medical activities family members in particular medical knowledge and skills mother, play an important role in the formation of the health of children. If medical knowledge of the members family recommendations doctor in this family run completely in a timely manner, are systematic preventive examinations. It installed children in families with regular systematic preventive examinations in 2 times less likely to sick than children in families without regular systematic preventive inspections.

One of the most important objectives in relation children's health all ages is to identify parents when the first sign disease timely visits to the doctor, their regular visit full and complete treatment knowledge parents prevention of diseases provide first care and Patient can arrange proper the care of the child.

According to our research, the risk of diseases increasing 2.5-3 times in families with irregular parents irregular visits and those who do not understands execution medical and hygienic recommendations or feel yourself responsible.

Due lack knowledge of parents in the field prevention diseases family do not accept active measures in this direction. The result increases the risk of birth children with disabilities development such families. 
Such factors as the prevention and treatment diseases ability parents to provide first aid and patient care child, important to maintain and strengthen the health of children. It should be noted, what are the factors increase medical care and medical activity parents especially regular preventive examinations have crucial to maintain and strengthen the health of the child.

This way results research show what you need to take an active measures to improve lifestyle children develop target measures to increase medical activity families first turn on protecting and promoting the health of children.

Scientists and the doctors almost all countries working on problem diagnosis and treatment of congenital anomalies. For the last 10 years prospects pathogenesis congenital anomalies dramatically changed. According to statistics, in the Republic of Uzbekistan congenital anomalies amounted to 8.5 to 16.8 per 1000 births. Most common congenital anomalies are congenital anomalies of the lips and heaven: 1: 745 in Tashkent and 1: 510 in Karakalpakstan.

Pathological the karyotype the mother is a risk factor formation the same pathology fetal and requires mandatory his karyotyping, which is also considered successful implementation program prevention congenital and hereditary diseases.

You need strict adherence to algorithm survey pregnant risk groups in relation to birth they children with disorders development starting with I trimester pregnancy: genetic business, if necessary karyotyping pregnant definition the level of serum alphafetoprotein, diagnosis intrauterine infection ultrasonic the study in I and II trimesters pregnancy according to the testimony invasive prenatal procedures (chorionic villus sampling, amniocentesis).

The lack of common methodological treatment congenital malformations is essential the disadvantage research study the dynamics of their prevalence. This leads to noncomparability data obtained different researchers.

Was conducted a series of scientific research to explore the prevalence and clinical aspects of innate anomalies. Though that recent years was held a few scientific research and achievements, directed the diagnosis and treatment diseases the study of the nature disease Uzbekistan could not adequately to prevent congenital anomalies in this region. In addition also, the prevalence of congenital anomalies analyzed only with the help of medical survey (screening) pregnant women.

In the same time one of the main the reasons for the increased the risk of congenital defects congenital anomalies is the fact that pregnant the woman is not is timely medical inspections although it is allowed by law, the prevalence of extragenital diseases women and pregnancy without nurses, including nursing nurses, when conduct integrated dispensary observations including lifestyle quality of life is not comparative evaluation activities. 
Figure 9. Common the incidence of innate anomalies among children of Tashkent (per 1,000 children)

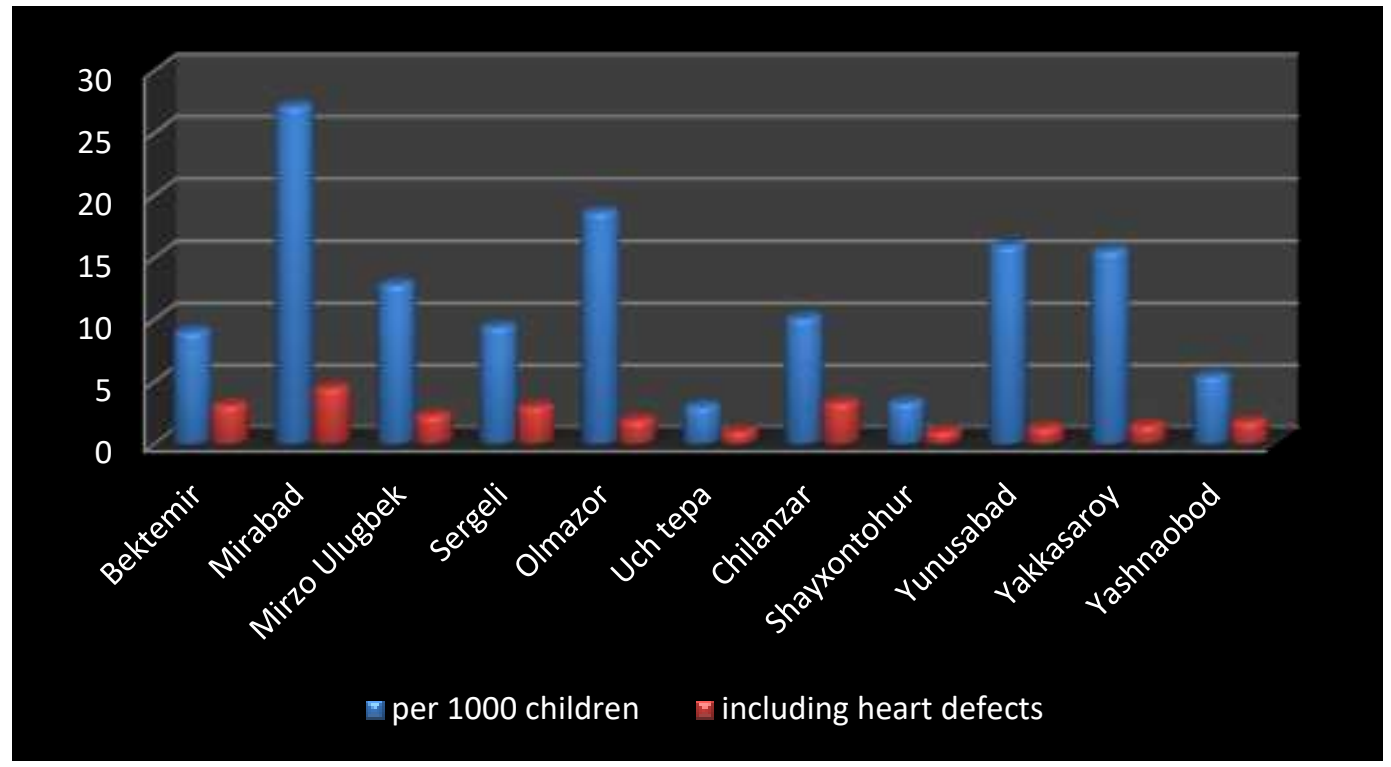

Medical patronage - complex events implemented doctor or nurse at the home of the patient, tasks which are treatment patient prevention he's different diseases as well as consulting. Primary patronage newborn is according to the Order The Ministry health and resolution Of The Cabinet Of Ministers from September 132017 No. 718 on the order conduct rating evaluation of the effectiveness of activities Central district (city) multidisciplinary clinics, urban and rural family clinics, rural health and medical and medium medical staff. Information about the content the first patronage to the newborn recorded in the history of child (f. No. 112) under "First patronage to the newborn". Precinct nurse family clinic visits pregnant the woman immediately after setting on the account in female advice to assess the conditions under that is pregnancy as the family prepares birth child, primary the objective of the patronage at this point is business. In the middle third trimester nurse must come again to check whether her recommendations and advises the mother for questions newborn care and breast feeding. In the 1-2 day after extract mother's and child first pediatric patronage to newborn performs the district pediatrician and nursing sister. About because in the territory, accepted certain child care center appeared newborn patient, medical institution informs a maternity hospital. Senior medical sister child clinics, after receiving information about discharge baby from the hospital, the same day logs in journalregister.com newborns; fills the history of the development newborn cast in her ear prenatal of patronage, guide development the registry or directly precinct medical sister. Primary patronage is at the address where actually the child lives independently address registration. System free nursing observations apply all newborn independently of parents permanent registration and the policy of compulsory medical insurance. 
Goal primary patronage newborn:

- $\quad$ rating state health and child development,

- business parents to care for a newborn,

- business and practical assistance in the organization feeding newborn assistance in breast feeding,

- $\quad$ prevention common childhood diseases (rickets, anemia etc.)

- recommendations in relation to preventive examination of the child to construction year pediatrician and doctors and preventive vaccination.

First patronage to newborn must be not implemented later 1-2 days after discharge from the hospital; discharged premature children with symptoms perinatal and congenital pathology the nurse and the district doctor visit already on the day of discharge. If this day have for the weekend or holidays, the child attends the doctor on duty pediatrician. For visit newborn doctor and nurse needs to clean disposable bathrobes or reusable the robes that stay on home have a newborn for their purity watching mother. The robe is returned mother in first visit children's clinic upon reaching a child 1 month. History includes collection social, biological and genealogical information. Estimated the completeness of the family and psychological the climate there, housing conditions and their sanitary level, and condition the health of the mother features antenatal period, genealogical history - the state the health of parents and relatives (at least 3 generations), bad habits. Mother passes the doctor part the card exchange (information of the child), received at discharge from the hospital the house in which see information about pregnancy and delivery condition child with birth (est Apgar), the main parameters physical development (weight body length body, circumference head and chest cells), data on holding preventive vaccinations and their absence and the reasons contraindications to conduct preventive vaccinations, if they are not posted.

The role nurses with extensive awareness the factors risk impact the quality life and health pregnant women plan and procedures prevention congenital anomalies not developed. It was not designed no comprehensive science-based measures to improve health children. 
THE AMERICAN JOURNAL OF MEDICAL SCIENCES AND PHARMACEUTICAL RESEARCH

ISSN (e): 2689-1026

DOI: https://doi.org/10.37547/TAJMSPR/Volume02Issue07-09

Common The Incidence Of Innate Anomalies Among Children Tashkent (On 1,000 Children) 2014-2018.

Table 3

\begin{tabular}{|c|c|c|c|c|c|c|c|c|c|c|}
\hline \multirow[b]{2}{*}{ Thepod } & \multicolumn{2}{|l|}{2014} & \multicolumn{2}{|l|}{2015} & \multicolumn{2}{|l|}{2016} & \multicolumn{2}{|l|}{2017} & \multicolumn{2}{|l|}{2018} \\
\hline & 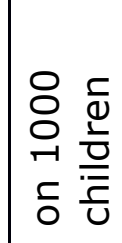 & 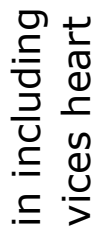 & 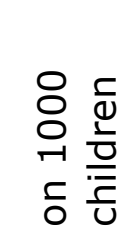 & 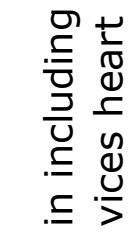 & 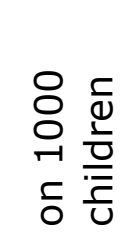 & 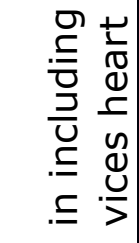 & 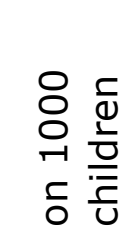 & 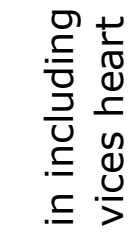 & 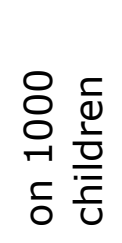 & 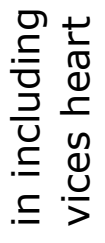 \\
\hline Bektemir & 7 & 2,4 & 3,6 & 2,0 & 6,8 & 3,3 & 7,8 & 3,8 & 9,0 & 3,1 \\
\hline Mirabad & 17,1 & 3,9 & 18,7 & 4,4 & 23,0 & 4,8 & 30,7 & 4,8 & 27,1 & 4,5 \\
\hline $\begin{array}{l}\text { Mirzo } \\
\text { Ulugbek }\end{array}$ & 18,4 & 3,8 & 26,3 & 3,0 & 20,5 & 3,2 & 30,9 & 4,2 & 12,8 & 2,3 \\
\hline Sergeli & 15,3 & 4,9 & 9,9 & 3,5 & 9,9 & 3,6 & 10,3 & 3,9 & 9,4 & 3,0 \\
\hline Olmazar & 26,8 & 2,2 & 24,5 & 1,9 & 22,1 & 2,0 & 20,4 & 1,8 & 18,6 & 1,9 \\
\hline UchTepa & 2,5 & 0,6 & 2,9 & 0,7 & 2,9 & 0,6 & 2,8 & 0,7 & 3,0 & 1,0 \\
\hline Chilanzar & 10,9 & 3,4 & 18,9 & 3,2 & 9,4 & 2,9 & 10,7 & 3,2 & 10,1 & 3,3 \\
\hline Shayxontohur & 3,7 & 1,5 & 3,6 & 1,3 & 3,5 & 1,0 & 3,7 & 0,9 & 3,3 & 1,0 \\
\hline Yunusobod & 23,2 & 3,9 & 19,4 & 2,5 & 19,4 & 2,4 & 18,1 & 1,4 & 15,9 & 1,3 \\
\hline Yakkasaroy & 26,9 & 3,5 & 21,0 & 3,4 & 18,8 & 2,1 & 12,4 & 1,7 & 15,5 & 1,5 \\
\hline Yashnaobod & 14,8 & 2,7 & 7,1 & 1,9 & 5,9 & 2,1 & 5,9 & 2,4 & 5,4 & 1,8 \\
\hline Total & 15,2 & 2,8 & 14,7 & 2,3 & 12,9 & 2,2 & 13,7 & 2,2 & 11,1 & 2,0 \\
\hline
\end{tabular}

Based on this, is prevention and early detection congenital anomalies in institutions primary health help identifying the leading factors risk flash disease system the approach to prevention diseases increase quality of life and quality of life of the population. The role of nursing nurses in ensuring the closest and direct communication with the population working doctors.

General practice institutions primary medical assistance is important to implement the above.

Patronage is form work treatment-and-prophylactic institutions the main objectives of which are holding home health and preventive events introduction the rules of personal hygiene and improvement sanitary conditions in the home. Especially widely patronage is used in institutions maternity and childhood, some the dispensaries. Is doctors, precinct (nursing) sisters baby clinics, dispensaries and rural medical plots by paramedics and midwives women's clinics and midwifery points.

Patronage pregnant- composite part of the system dispensary observations for pregnant woman, the purpose which is implementation complex events directed on the formation, save and strengthening the health of the mother warning development she diseases and 
complications pregnancy early detection, treatment and the provision of conditions for normal the development of the fetus.

Efficiency held in the women's advice (Female advice) events health pregnant and prenatal the protection of the fetus the most high, when they are in the early periods and conducted systematically throughout pregnancy. In addition, it is allows the doctor right to determine pregnancy and maternity home away from home. Installed a clear correlation between the level perinatal mortality and the number and regularity visits pregnant advice.

In pregnancy if its physiological for a woman a must visit obstetrician-gynecologist an average of 14 times.

After the first inspection the turnout is assigned 7-0 days (the results analysis, conclusion therapist and other professionals); in the future in the first half pregnancy - 1 time per month; after 20 weeks - 2 times; after 32 weeks - 3-4 times.

When visit pregnant women's consultation the doctor and the midwife have the opportunity appreciate it state dynamics of growth body mass the blood pressure tests urine, etc. On the status of the fetus judged according ultrasonic and other special research. In identifying a pregnant somatic diseases complications pregnancy the frequency of observation and volume surveys increase.

If the woman is in the women's advice irregularly or not attending the doctor at the appointed term, especially in the presence of pathology pregnancy the midwife carries patronage, finds out the reason for the absence, measures blood pressure and invites on reception to the doctor. The patronage is carried out also in case of refusal women hospitalization. In this case the doctor or midwife explain the woman or her family relatives the danger to where can lead violations able women's health and fetus, as well as reminds of responsibility for the rejection hospitalization. The doctor assigns appropriate therapy and continues watch pregnant at home. When visit pregnant at home doctor and the midwife give recommendations nutrition personal hygiene, the participation of women in the home the work, based on conditions family life and health women.

Results patronage, the date its implementation recorded in Individual map pregnant women (form No. 111/y). Patronage pregnant can realize and doctor if woman as health is not can visit advice or need her inspection doctor at home identified midwife when you patronage.

In regions a high birth rate, with a significant the number of many women giving birth on the site to implement patronage pregnant stands out special nursing midwife.

Patronage pregnant exercise also nurses family run clinic. Information about pregnant in Semenya the clinic come from female consultation. Nurse visits pregnant twice: the first times during 10 days after receiving information about it female advice the second time on 31 - 32 weeks pregnancy. The purpose of the patronage: install contact family clinic 
with a future mother to meet you conditions the life of the child, assess social position family, and hygienic condition apartment, to find out condition the health of the mother give her the necessary recommendations in the mode of labour, rest, nutrition, for the preparation of the area for newborn to teach the rules feeding and care newborn, control regularity visit woman school young mothers. Upon detection social difficulties family nurse can guide the woman on advice for the legal counsel.

Patronage children are each pediatric the site as a pediatrician and precinct sister either as a medical assistant. The main tasks the patronage kids at home are early diagnosis initial deviations able children's health and timely appointment Wellness and corrective events control implementation nursing mother for a newborn and his feeding.

First times pediatrician and nurse visit the school on 2-3rd day after the extract of its of obstetric hospital then once a week. The district pediatrician examines of the child to the first month life $3-4$ times. In some regions of the country the first inspection newborns the district pediatrician is in the delivery house. Nurse attends child in the first week 2 times, then weekly on average the first month at least 5-6 times. In the past weeks first month of life the child should to be viewed in the children's clinic in a specially reserved to receive day. During the patronage given tips on the rules hygienic newborn care, sleep mode, waking feeding prevention hypogalactia, pustular diseases skin. Together mother produced tactics observation for a newborn given the current pregnancy delivery, terms and conditions the life of the family. Nurse should pay attention to care pumping mother milk behavior the child after feeding. Quality specified work depends on from a professional the level of medical staff children's clinic. Observation for a child the first month life, all kinds medical care are only at home. In the organization observations for newborns on the site special attention drawn for children born mothers group high risk perinatal pathology. In further the patronage of children doctor or nurse can be organized according to the testimony (for example, after moved diseases).

On the village of patronage children up to 1 year performs nurse. It controls rational feeding the child, organizing events prevention rickets and malnutrition preventive vaccinations, conducts work to increase sanitary culture mother. Results the patronage recorded in the outpatient card or nursing notebook.

\section{Conclusions}

Medical the patronage of children the first month life and future observation with performs pediatrician rural medical station, remote areas pediatrician visiting medical brigade of the Central district hospital.

Experienced and trained the nurse may become not only assistant the doctor in the treatment children, but also the main help families in the organization care, nutrition, control physical and psychomotor development of the child, training conduct correctional events at various border and functional States peculiar children first months of life. 


\section{ISSN (e): 2689-1026}

DOI: https://doi.org/10.37547/TAJMSPR/Volume02Issue07-09

Unprofessional nursing care in the postoperative period can cause an increase in its duration and lead to an adverse outcome. Inattentive attitude to the first deviations in the condition of children in the period after surgery can sometimes cost the patient's life. The main role of managing the postoperative period belongs to the nurse, who not only performs timely doctor's appointments, but also takes care of children. The nurse is constantly in the patient's room, so most often notices the slightest changes in his condition and is sometimes forced to independently provide first aid. The duty nurse also includes training in rules of care for the patient and his family members. Let's consider the features of nursing care in the postoperative period for children with congenital malformations of the maxillofacial region.

Medical nursing service plays an important role the protection of the health people, prevention diseases and the protection of the health our people. Many medical and social problems in the society will prevented if the work in this direction will be for the necessary level. In particular, will be achieved significant results in the prevention maternal and infant mortality a sharp decline in congenital anomalies, making decisions about healthy lifestyle in society. So it will be developed a plan to raise nursing service on the new level based on such an important criteria.

At to him, now patronage the work will be in three stages. On the first stage the population examined every six months. It determines the segment of the population, need in philanthropic support. On the second stage in people's homes will be organized targeted nursing events with the participation of nursing nurses doctor total practices and specialists. It covers lonely elderly people in need in the waiting room family, disabled and others in need care, children in the age of 1 year and persons with disabilities pregnant women new mothers. Target patronage organized every week in accordance with a certain plan.

In organization the third stage patronage events staff primary health aid direct help scientists regional and national medical institutions and specialized research centers. Now time event is monthly and covers patients with chronic diseases in need in a specialized medical help. According to from disease outpatient or stationary treatment is provided in the district, regional and national institutions. Nursing nurse regularly works with pregnant women to provide information on the origin congenital the anomaly and its prevention.

Development phased integrated system approach to primary secondary and tertiary stage; to establish program to the algorithm events early identifying and prevention congenital anomalies and give practical recommendations on the formation of the population skills healthy lifestyle; identification risk groups population which allows to conduct a comprehensive the assessment of the degree risk factors influencing the formation of polar anomalies in activities family health clinics. 


\section{References}

1. Rizaev J. A., Nurmamatova K. H., Dosmuhamedov D. M., Mirzarahimova K. R. Tum of anomaliesare Bolalarorasida taralis. // Dentistry No. 12019 http://dx.doi.org /10.26739/2091-S845-2019-9

2. 1234 Wei Cui, Chang-Xing Ma, Yiwei Tang, e.a. (2005) Sex Differences in Birth Defects: A Study of Opposite-Sex Twins. BirthDefectsResearch (Part A) 73 p. 876-880.

3. Received the data are consistent with the results research Kozlova V. I. et al. (1995)

4. Mirkarimova L. T., Nurmamatova K. H, Mirzarahimova K. R. Medical management, optimization and improvement health system in Uzbekistan // Dentistry No. 4, 2018 http://dx.doi.org/10.26739/2091-5845-2018-1-27

5. Rare form aneurysms aortic arch V. Arakelyan, N. A. Gidaspov, V. G. Papitashvili Patologiâ Krovoobrašeniâ i Kardiohirurgiâ.2016; 20(4):16-25 DOI 10.21688/16813472-2016-4-16-25

6. The phenomenon child disability in context quality life population Olga Nikolaevna Potapova Sovremennye Issledovaniâ Social'nyh Problem. 2015; 0(4):524-536 DOI 10.12731/2218-7405-2015-4-46

7. Ebstein's anomaly in children: A single-center study in Angola Valdano Manuel, Humberto Morais, Manuel Pedro Magalhães, Maria Ana Sampaio Nunes, Gilberto Leon, Manuel Ferreira, António Pedro Filipe JúniorRevista Portuguesa de Cardiologia. $2015 ; 34(10): 607-612$

8. Mirzarahimova K. R., Nurmamatova K. H, Prevention of dental diseases in women during pregnancy, Medicine tomorrow day Materials XVI международной scientificpractical conference students and young scientists. 2017, Chita. 414-415c

9. Medical Thesis http://medical-diss.com/medicina/vzaimodeystvie-semi-i-meditsinyv-sovremennom-obschestve\#ixzz6IIrD509q

10. Atoev M. A. The impact of environmental environmental factors the development dental abnormalities in children and development treatment-and-prophylactic events (for example, Mr. Zarafshan and Bukhara) abstract. dis. kand. med. Sciences :14.00.21 / M. A. Atoev; MOH of RUz, Tashkent Medical Academy. - Tashkent 2007 19

11. Ergashev, B. B. Diagnosis and treatment of disease development of the kidneys newborns and infants: abstract. dis. d-RA med.Sciences:14.00.35 / Bakhtiar Bigalievich Ergashev ; Resp. spec.center surgery them. V. Vakhidov. - T, 2007. - 39 
12. Professional deformation the identity of nurses Article. Scientific discussion: Issues in medicine A collection of articles materials XXXVI international correspondence scientific-practical conference No. 4. (27) April, Moscow-2015

13. nfuence of Physical Activity and Harmful on Male Sexual Function. Article.WHP World Healthcare Providers a Multidisciplinary medical journal USA. Vol.6. No. 2, April 2015.p.47-51.5

14. The prevalence and risk factors cardiovascular diseases young people age. Article. Scientific discussion: Issues in medicine A collection of articles materials XXXVIIXXXVIII international correspondence scientific-practical conference № 5-6.(28) June Moscow-2015. -S. 7-15.

15. Integrated the study of the state of health forecasting risk factors and development multilevel program prevention child disability. Article Research journal No. 15 (95)."Young a scientist."Moscow, Kazan.August 1, 2015.-Page 283-287.

16. The volume samples for populationage study urological morbidity. Article. Experimental and clinical urology № 1.Moscow-2015. -C. 1-5.

17. K.R. Mirzarakhimova, K.C. Nurmamatova Prevention Of Dental Diseases In Women During Pregnancy Medicine tomorrow day, 418-419

18. S.Sayfullaeva, A.SH Mamadou Results and Problems Introduction Newborns With Congenital Heart Defects to conduct I-international scientific-practical online conference"Actual questions medical science in XXI century"

19. D.A. Kasimova, K.R. Mirzarahimova Factorof diet in the development and prevention congenital anomalies TA-nabedrennik joints. Muharrir the Minbariuu VA Etisalat

20. Mirzarahimova K. R. Electromyography as a method functional diagnosis dental anomalies III international youth scientific-practical forum "Medicine the future: from development to application" dedicated 75th anniversary Orenburg state medical University. 508 article.

21. Mirzarakhimova K. R. Congenital dent facial anomalies. I- international scientificpractical Internet conference "Actual questions medical science in XXI century" 219$223 \mathrm{St}$

22. Mirzarahimova K. R. To learn statistics congenital dental anomalies I- international scientific-practical Internet conference "Actual questions medical science in XXI century" 152-157ct 
23. Mirzarahimova K. R., Nurmamatova K. CH, The prevalence dental diseases mouth among pregnant women."ACTUAL PROBLEMS OF MODERN DENTISTRY" Samarkand medical Institute, 2017

24. Mirzarahimova K. R., Nurmamatova K. CH, the question on the prevalence functional disorders dental system in children, XII International (XXI AllRussian)Pirogov scientific medical conference students and young scientists Moscow, 2017120 c 